\title{
The View from Nowhen: The Mctaggart-Dummett Argument for the Unreality of Time
}

\author{
Kevin Falvey
}

Received: 12 January 2009 /Revised: 14 September 2009 / Accepted: 17 September 2009 /

Published online: 9 January 2010

(C) The Author(s) 2009. This article is published with open access at Springerlink.com

\begin{abstract}
Years ago, Michael Dummett defended McTaggart's argument for the unreality of time, arguing that it cannot be dismissed as guilty of an "indexical fallacy." Recently, E. J. Lowe has disputed Dummett's claims for the cogency of the argument. I offer an elaboration and defense of Dummett's interpretation of the argument (though not of its soundness). I bring to bear some work on tense from the philosophy of language, and some recent work on the concept of the past as it occurs in memory, in an effort to support the claim that McTaggart is not guilty of any simple indexical fallacy. Along the way I criticize an account of what is at stake in disputes about the reality of tense due to A. W. Moore, and I argue for the superiority of the conception of tense-realism that is implicit in McTaggart's work. The paper is intended to prepare the ground for a substantive defense of the reality of tense.
\end{abstract}

Keywords Time $\cdot$ Tense $\cdot$ McTaggart $\cdot$ Reality $\cdot$ Dummett $\cdot$ Indexicals $\cdot$ Point of view

\section{McTaggart's Argument}

Some years ago, Michael Dummett defended J. M. E. McTaggart's argument for the unreality of time, offering an interpretation of the puzzling second part of the argument according to which there is at work in the reasoning a suppressed premise, to the effect that there must exist in principle a complete description of

K. Falvey $(\bowtie)$

Department of Philosophy, University of California, Santa Barbara, CA, USA

e-mail: falvey@philosophy.ucsb.edu 
reality. ${ }^{1}$ Dummett suggested that viewed in this way, the argument is cogent, and cannot be dismissed as simply based on a confusion in the syntax and semantics of the indexical expressions, 'past,' 'present,' and 'future.' In a more recent paper, and in subsequent discussions, E. J. Lowe has disputed Dummett's claims for the cogency of McTaggart's argument, and renewed in a sharp form the charge that the reasoning turns on some fundamental misunderstandings of the logic of the crucial A-series predicates. ${ }^{2}$

In this paper I offer an elaboration and defense of Dummett's interpretation of McTaggart's argument, although I shall not defend its soundness. I bring to bear some work on tense from the philosophy of language, and some recent work on the concept of the past as it occurs in memory, in an effort to support the claim that McTaggart is not guilty of any simple indexical fallacy. Dummett's interpretation of McTaggart already borders on the excessively charitable, with its substantial additional premise. I shall be departing even more substantially from the original text, so I call my argument the "McTaggart-Dummett" argument. I leave others to judge whether I am being excessively charitable to Dummett.

We may begin with Lowe's formulation of the original McTaggart reasoning:

(1) Time essentially involves change

(2) Change can only be explained in terms of A-series expressions.

(3) A-series expressions involve contradiction and so cannot describe reality.

(4) Therefore, time is unreal.

The first premise is relatively uncontroversial. The same cannot be said for (2). Both Dummett and Lowe accept it, so it is irrelevant to the dispute between them. But it is often regarded as the weakest link in McTaggart's argument. McTaggart's (1921) rejection of Russell's proposed B-theoretic account of change is widely viewed as unpersuasive. My own view, in fact, is that (2) is probably false. So why should we care about the dispute between Lowe and Dummett over the interpretation of the argument if we think it is unsound anyway because of the falsity of (2)? The answer is that the second part of McTaggart's argument retains its interest as an argument against the reality of tense, which may be considered and evaluated quite independently of any force it might have, in virtue of (2), in a further argument against the reality of time in general. A version of the second part of McTaggart's argument has even been endorsed by D. H. Mellor, as showing the unreality of tense, even though Mellor rejects (2) and the further conclusion that time is unreal. So the proper interpretation of this part of the argument is well worth studying, and the dispute between Dummett and Lowe is a good way of engaging with the relevant issues. Those issues involve the proper understanding of tense, and more generally, indexicality. Many philosophers are dubious that investigating tense or other aspects of our folk theory of time can tell us much of interest about time as it is in itself. But even one who thinks so can agree that the proper understanding of tense - and hence the dispute between Dummett and Lowe - is highly relevant to the question whether tense is real. I propose then, that we set aside the question of the soundness of the overall argument, and focus on what, if anything, it has to teach us about tensed

\footnotetext{
${ }^{1}$ McTaggart 1908, Dummett 1960.

${ }^{2}$ Lowe 1987.
} 
speech and thought, and the extent to which such speech and thought is adequate to the representation of reality.

At issue, then, is the interpretation and evaluation of McTaggart's argument for (3). The reader will recall that McTaggart asserts (3) initially on the strength of the fact that any event, such as the coronation of Queen Anne, has all three of the properties, past, present, and future, contradicting the fact that the logic of these notions renders these properties incompatible. The rest of the reasoning prosecutes a regress argument against the rather obvious response to this claim. The obvious response is that the coronation does not have all three of these properties at the same time: it is (now) past, it was present, and it was (at still other times) future. McTaggart claims that this can only mean that the event is past in the present, and present in the past, and future in the past. The defender of the A-properties is now committed to defending the consistency of the nine second-order tense properties that result from choosing two from among the three initial tenses. These are not all supposed to be mutually incompatible, but some pairs of them are, and McTaggart claims once again that every event has them all. This conclusion can be avoided, he says, only by appealing to the twenty-seven third-order tenses, and so on. The regress that results is vicious because there is no stage at which the contradiction is finally resolved.

The brunt of Lowe's criticism of McTaggart is directed at the very idea of such locutions as "past in the present" and the related ones italicized in the preceding paragraph. McTaggart's appeal to such locutions manifests, according to Lowe, a misunderstanding of the logic of tensed locutions, in particular, their indexicality. Talk of an event being "future in the past," according to Lowe, is as ill-formed and unintelligible as talk of a thing being "here over there." One can say that the sentence, 'Ronald Reagan's death lies in the future' was true at certain times in the past, just as one can say that the sentence, 'my car is here' is true if uttered over there (pointing in the direction of the garage where my car is parked). But it is just a usemention fallacy to move from these acceptable statements to talk of objects or events as here over there or present in the past.

Now, I do not want to deny that there is a point to be made of the sort that Lowe makes. The use-mention distinctions that he draws attention to are valid and important. Dummett's sympathetic exposition of this part of the argument invites special criticism, as some of his formulations seem to run roughshod over these distinctions, moving back and forth between used and mentioned occurrences of the crucial terms. ${ }^{3}$ On the other hand, one may wonder whether the grammar of ordinary language should be accorded such supreme authority in matters of metaphysics. It would hardly be surprising if reflection on the nature of time were to lead us into territory where we feel a need to say things that sound bizarre if judged by ordinary standards. I will come back to this issue shortly. But first I wish to note that, remarkably, Lowe's entire discussion of Dummett's interpretation of the argument barely mentions the crucial premise that Dummett supplies on behalf of McTaggart, to the effect that that there must be a complete description of reality. There can be little doubt that this has some bearing on what McTaggart is up to with his strange

\footnotetext{
${ }^{3}$ See e.g., Lowe 1987, 4.
} 
compound tenses - or at least, on what Dummett thinks McTaggart is up to- - so we must devote some space to understanding what this premise involves.

\section{The McTaggart-Dummett Argument}

I take the overall structure of the argument to be as follows:

(1) Time essentially involves change.

(2) Change can only be explained in terms of A-series expressions.

(3') A-series judgments cannot be understood except in relation to a point of view.

(4') What cannot be understood except in relation to a point of view cannot figure in a complete description of reality.

(5) Only what can figure in a complete description of reality can be said to describe reality at all.

(6) Therefore, time is unreal.

The first two premises are brought over from our first formulation, and for reasons noted above, are not our interest here. It's the second part of the argument, which tries to show that tense is in some sense unreal, that is our concern. The charge leveled against tensed or A-concepts ${ }^{4}$ is that their connection to points of view renders them unsuited to inclusion in a "complete description of reality." I suggest that the notion of a complete description that Dummett has in mind is essentially what Bernard Williams calls the "absolute conception of reality," and what Thomas Nagel (1989) has discussed under the heading of "the view from nowhere." It is, in Williams' words, "a conception of reality corrected for the special situation or other particularity of various observers." "This notion is associated, in the work of Williams and Nagel, with a distinctive conception of the project of metaphysics. The metaphysician's task, according to a tradition going back to Parmenides, is to characterize the way the world is in itself, and not to be content with characterizations that may reflect particular, idiosyncratic conceptions of individuals differently situated or differently equipped cognitively. Such differences give rise to differences of judgment that cannot be straightforwardly conjoined, but that do not reflect any underlying disagreement about the nature of reality. Color and sound predications, on one familiar conception of them, exhibit these features. I say that the apple is red and silent, while the Martian says that it is invisible but makes a humming noise (Martians lack vision but possess a sonar-like sensory modality such that microstructural properties of surfaces produce in them various types of auditory experiences). Given the logic of these notions, it would be contradictory to simply conjoin these judgments. On the other hand, we do not want to say that the Martian and I disagree, in the sense that at least one of us must be mistaken. We need to find a way to express the fact that there is a single reality on which we do not disagree, but which we represent differently due to our different cognitive equipment. We do this by stepping back to form a conception of reality that includes the judgments and

\footnotetext{
${ }^{4}$ I do not distinguish between tense and A-series concepts, although I recognize that there are ways of understanding these notions according to which they are not exactly the same.

${ }^{5}$ Williams 1978, 241.
} 
a characterization of the perceptual equipment of the beings that make them. We say that the apple is disposed to produce a reddish appearance in the human, and it is disposed to produce a humming auditory experience in the Martian. The absolute conception of reality is the limit that we approach as we correct, in this and similar ways, for more and more of the idiosyncrasies of the limited and partial conceptions of reality that rational beings hold. ${ }^{6}$

Ordinary tensed judgments quite obviously reflect the judgers" "special situation"in this case, their positions in time. Suppose Nancy Reagan's astrologer said in 1984, "your husband will live for another 20 years," while somewhere today (September, 2009) a schoolteacher tells her class, "President Reagan died 5 years ago." These judgments cannot simply be conjoined and added to the overall description in The Big Book of Reality, to whit: "Reagan died 5 years ago and he will live for another 20 years." That would contradict the fact that a person cannot continue to live after he has died. But, again, we want to say that the astrologer and the schoolteacher do not really contradict one another. In fact, both of their judgments are true. To express this, we ned to take into account their different temporal situations vis-à-vis the underlying facts concerning Reagan's life and death. We step back and form a conception of reality broad enough to include the judgments and their relations to their judgers' positions, just as we did in the case of the secondary qualities.

This line of reasoning assumes, of course, that there is a single temporal reality that both the astrologer and the teacher are citizens of and are commenting upon. This rules out presentism, for that would entail that the astrologer does not (now) exist, and so her judgments present no problem. We can simply note that it is true (now) that 25 years ago President Reagan still had 20 years to live. If our concern is with the historical McTaggart, the fact that (5) entails the falsity of presentism is hardly an objection to Dummett's interpretation of his argument, since it is beyond doubt that McTaggart does not consider presentism to be a viable metaphysical theory of time. McTaggart regards it as an obviously necessary feature of temporal reality that it must constitute a B-series, wherein all the events in the field of the earlier-than relation are equally real. In fact, McTaggart's clear view that time must constitute a single series of this sort is strong evidence that he is indeed committed to (5), for the B-series embodies precisely the kind of complete, Parmenidean "view from nowhen" that (5) asserts is the sine qua non of the genuinely real. In this respect McTaggart is in agreement with what modern physics seems to tell us about time (or space-time), and presentism is notoriously difficult to reconcile with the physical facts as we have them. Indeed, the problem McTaggart sets up seems to anticipate more recent attempts at integrating tensed or A-concepts into an overall view of temporal reality based on an underlying B-series. For McTaggart thinks it necessary, for the B-series to be genuinely temporal, that the A-series concepts be mapped somehow onto it. In the denouement, this proves to be impossible and spells disaster for tense (and by (2), time). The reasoning is quite similar to arguments for the unreality of tense as presented by Putnam 1967 or Mellor 1998, with the exception, of course, that these philosophers do not draw the further conclusion that time itself is unreal, because they reject (2). Confirmed presentists will not, I'm afraid, be much

\footnotetext{
${ }^{6}$ For criticism of the Nagel-Wiiliams ideal of the absolute conception of reality, see Stroud 2000.
} 
moved by the McTaggart-Dummett argument, but in view of the problems that beset presentism, I do not think this deprives the argument of much of its interest.

Let's return to the main thread. I suggested that McTaggart is searching, in the second part of his argument, for a way of integrating incompatible but not contradictory tensed judgments into a single conception of reality, where the problem is in certain respects analogous to that of integrating incompatible but not contradictory judgments about sensory qualities. We can use the analogy to shed light on the respect in which tense may turn out to be "unreal." Recall that the metaphysics of colors and sounds is controversial, and there are various ways the story of these and similar qualities might turn out. It may be that the only coherent and accurate absolute characterization of what is going on in the case of the human and the Martian will dispense entirely with color terms ('red,' 'chartreuse') and phenomenal auditory terms ('humming,' 'crackling'), and revert to a vocabulary of reflectance distributions, retinal stimulations, wave frequencies, and inner ear bone vibrations. This would establish, given the parameters of the discussion, that colors and sounds are not real. An analogous point holds for the tensed predicates. If the only way of forming a unitary conception of time that reconciles the disparate judgments of differently situated individuals is to revert to a vocabulary that dispenses entirely with the notions of the past, present and future, and inflections on verbs that express these notions, then tense will have been shown to be "unreal" (and time itself if (2) is accepted). The unreality of tense amounts to what we would nowadays call eliminativism about tense, to be understood analogously to the more well-known metaphysical doctrine of eliminativism about color (e.g., Hardin 1988). ${ }^{7}$

This helps us to see how we should regard the perhaps awkward compound tense predicates that figure in the second part of McTaggart's argument. They are motivated by the need to incorporate, in some way or other, the concepts of past, present, and future into the absolute conception of temporal reality, in order to give tense (and hence time itself on McTaggart's view) a fighting chance at being real. If we cannot do this - that is, if we find we can only describe the underlying temporal reality consistently by dispensing with tensed talk and reverting to B-series notions, then we will have to admit that tense is unreal. On this way of looking at the matter, the talk of the A-series predicates as being "contradictory" need not be taken too seriously. We can simply note that the judgments of the astrologer and teacher, both of which we wish to count as true, raise the question of how to relativize them, if possible, in a way that carries over to the absolute conception their tensed content. If we find that the best we can do is to say that Reagan's death IS, tenselessly, 20 years later than 1984 and it IS 5 years earlier than 2009 , then the tensed notions will have been found unworthy and thereby unreal. (In what follows, verb forms in capital letters are to be understood as tenseless.)

This is what we must conclude, according to the McTaggart-Dummett argument, for there is no way of stating consistently and coherently all the tensed truths expressed by speakers or thinkers differently situated in time, in terms that still retain some measure of tensed content. There are two crucial steps in the reasoning - the rest is mere iteration. First, McTaggart suggests that the defender of the A-notions may try to say that 25 years ago Reagan's death was 20 years in the future, and the death is now 5 years in the past.

\footnotetext{
${ }^{7}$ An analogy with the metaphysical status of colors is also deployed in an attempt to understand McTaggart's reasoning in Healey 2001.
} 
This description is consistent, and retains the A-notions. But in light of the previous discussion, we can see that it obviously does not give us everything we need in order to save the tensed notions by vindicating their place in the complete description of reality. The suggested way of putting things introduces a particular point of view that in effect, mediates between that of the two judgers and reconciles them: it is the point of view of the present year, 2009. This point of view is still very clearly a limited and partial take on temporal reality. It has no special metaphysical status with regard to describing reality, once presentism has been set aside. It is only against the background of this situational fact, that we are presently situated in 2009 , that we can see the truth in this way of putting things. This characterization cannot then be taken up into the absolute conception of reality we are seeking. Another astrologer situated in, say, the 1930's, would have reconciled the judgments in different terms, and he would not thereby have been mistaken. His limited and partial view would be every bit as valid as ours. The absolute conception of temporal reality must be a view not tied to or intelligible only in terms of any particular position in time. What we seek is the "view from nowhen:" a statement of the facts - including the facts of how the astrologer and the teacher are situated with respect to the facts of Reagan's death - from no particular temporal point of view. ${ }^{8}$

The problem is the occurrence, in the proposed description, of the tensed forms of the copula: 'is,' 'was,' and 'will be.' These terms make a kind of reference to the times at which they are uttered or thought, and the contents of sentences in which they occur are intelligible only in relation to this speaker-time. To avoid contaminating our description of reality with such parochial matters of temporal position, we must banish tensed forms of the verb. But our goal is to retain their tensed content in some form, lest we be forced to admit that tense is unreal McTaggart-Dummett's suggestion is that we factor 'was' into (a) a pure, tenseless copula and (b) a pure predication of 'in the past.' Similarly for the occurrence of 'is,' with 'in the present' in the (b)-position. The result - and this is the second crucial step in the reasoning - is the proposal that the death IS future in the past and it IS past in the present. Though this is the best we can do, it turns out to be insufficient to vindicate the reality of tense. For this description is still true only against the background of the time at which we are speaking. The predicates 'future in the past' and 'past in the present,' and all the other compound tense predicates, also make reference to the speaker's time, in a way that robs them of "absolute" meaning. This comes out in the fact that for every event, no matter when it occurs, and any compound tense predication, there is a correct description of that event using that predicate, if we choose the right temporal vantage point for the description. Some of these descriptions are incompatible, so we need yet another dose of relativization. In this way, we are launched on a regress which spells doom for the A-predications.

This factoring of the copula is the step that Lowe inveighs against, as noted above. But whatever else might be said of it, I think we can now see that it cannot be dismissed as a misunderstanding or fallacy in reasoning about indexicals. The suggestion is motivated by the broad metaphysical assumptions we are working with. It is a good-faith attempt to find some way of incorporating the tensed content of judgments into the absolute conception of reality. If Lowe is right and this makes no sense, then McTaggart

\footnotetext{
${ }^{8}$ The phrase 'the view from nowhen' also occurs in Price 1996, where it is used to mark certain vantage point-invariant aspects of time.
} 
could justly say, "fine, then my task is even simpler: A-predications are not suited for the absolute conception, period." Above all, it hardly counts as a criticism of McTaggart to hammer away at the fact that the A-notions are "uneliminably indexical." 9 On the interpretation I am suggesting, that is precisely what McTaggart is claiming. That is their downfall. If we eliminate the indexicality we have no way of reconciling the disparate judgments made from different points of view. On the other hand, if we retain the indexicality, we can reconcile the disparate judgments in various, equally valid ways, by choosing different points of view on temporal reality. But each such description is only partial, and we never attain a single complete description, as long as we attempt to retain the tensed content of these notions.

The argument turns on a clash between the ineliminable indexicality of tense(3') - and the metaphysical principle that Dummett introduced into the discussion(5). (Premise (4') is really just a gloss on the idea of a complete description.) (5) is never made explicit in McTaggart, let alone defended. Dummett's claim, with which I concur, is that viewing it as implicit in the argument makes the best sense of what McTaggart is up to. What is interesting about this way of looking at the argument is that it proceeds by adhering to an uncompromisingly realist line on tensed judgments until the last step. Premise (3') insists that the point-of-view-bound character of tensed judgments is non-negotiable and must be taken seriously. This expresses one kind of realism about tense. Unfortunately, it turns out to be incompatible with what McTaggart regards as a higher principle of metaphysics, namely (5).

Are there other ways of understanding the "reality of tense" that might be consistent with the Parmenidean ideal? Does McTaggart-Dummett adhere to an unreasonably strong conception of what must hold in order for tense to be real? How exactly is the dependence of tense on a point of view to be understood, and how does this dependence manifest itself in ordinary tensed speech and thought? I wish to turn to these questions in the remainder of this paper. Doing so will further clarify the McTaggart-Dummett argument. To tip my hand a bit, I believe that anti-realism or eliminativism about tense is an untenable doctrine, but the McTaggart-Dummett argument is the best case for it that I know. In particular, it incorporates a defensible position on what is required for tense to be real-more reasonable than some other conceptions of the reality of tense to be found in the literature, as I hope to show. My aim in what follows is to prepare the ground for a substantive defense of the reality of tense which I hope to undertake in future work.

\section{What is the Issue of the Reality of Tense?}

The sort of realism about tense that (3') enshrines is the idea that if tense is to be taken seriously, then its point-of-view bound character must be respected. As I noted above, this is close to the claim that tense is essentially indexical. But McTaggart understands this indexicality differently from Lowe. Lowe's outright rejection of McTaggart's truck with such notions as "past in the future" stems from Lowe's assumption that the use of tensed verbs and predicates is always understood in relation to the time of utterance, and it is not possible to project oneself into a different temporal standpoint and make tensed

\footnotetext{
${ }^{9}$ Lowe $1987,6$.
} 
judgments from that point of view. That would be, as Lowe puts it, like trying to say that my car is here over there. McTaggart, in contrast, wants to allow for such projection to a distinct time in some form. He notes that this still leaves compound tense judgments dependent on a point of view, because the speaker's own point of view is always in the background. It is just not the only temporal point of view relevant to the interpretation of tensed judgments.

In this respect, McTaggart's understanding of tense is closer to that dominant in contemporary linguistics. Many tensed sentences of ordinary language require a theory of tense that allows for the speaker to situate events in temporal relations to times other than the present. This type of theory of tense dates back to Hans Reichenbach, who proposed that all tensed utterances require for their interpretation a reference time, as well as a speech time, and an event time. ${ }^{10}$ The simplest sentences that require all three times involve compound tenses such as the future perfect. In an utterance of 'I will have finished my paper by next Tuesday,' the reference time is next Tuesday, and the time of the event of finishing the paper is being located between then and the time of the utterance. The utterance amounts to something very like a projection into the future of the past perfect 'I have finished,' which we might well describe by saying that the speaker is claiming that his finishing the paper will be "past in the future," where the future in question is next Tuesday. A still more interesting case is the phenomenon known as sequence of tense. Notice that sentence (7) is ambiguous:

(7) Mary said that a unicorn was walking.

Oversimplifying a bit, this could mean either that Mary said, at some past time, "a unicorn was walking," or that Mary said, at some past time, "a unicorn is walking." "Here the reference time is the time of Mary's utterance, and the ambiguity is due to the fact that the event of the unicorn's walking could be located either (a) earlier than or (b) simultaneous with Mary's speech. In addition, both these events are located in the past relative to the utterance of (7). ${ }^{12}$ Again, the first reading amounts to the projection of a past tense utterance into the past. The availability of the second reading is of interest because it represents the updating of the tense of an utterance or thought in an effort to preserve its content at a later time. Frege held that it is possible, and frequently necessary, to do this. He wrote: "if

\footnotetext{
${ }^{10}$ Reichenbach 1947. See also Partee 1973 and Burge 1974 for additional discussion. The latter two emphasize that tensed utterances contain a form of demonstrative or deictic reference to times, including both speech time and reference time. This sort of view is hardly universal among philosophers of time. Michael Tooley suggested (in discussion at the "Time on Trial" Conference) that the notion of the present could occur in a proposition with a tenseless copula and an explicit (non-demonstrative) temporal reference. Thus, "In 1942 World War II IS present." I am afraid I find it hard to see why this proposition should count as tensed, or even as an A-predication, if this is a broader category. I do not see what difference of meaning there could be, for example, between this proposition and the proposition that in 1942 World War II IS OCCURRING, which I take to be fully untensed or B-theoretic. Perhaps the former suggests that the event is in progress, but that would seem to be a matter of aspect, not tense, and in any case, the latter proposition suggests this as well.

11 The oversimplification is of course that (7), on either interpretation, does not require for its truth that Mary spoke in English.

12 The same ambiguity, and complex temporal reference, is present in sentences that attribute certain intentional mental acts, e.g., 'Tom remembered that the stove was on.' For discussion of some of the semantic issues raised by these sentences, see Higginbotham 1995.
} 
someone wants to say the same today as he expressed yesterday using the word 'today,' he must replace this word with 'yesterday.' Although the thought is the same, its verbal expression must be different. . ."13 Not all philosophers have agreed with Frege that the result of making this replacement would result in the expression of the very same thought. But the possibility of understanding (7) in the second way given above would seem to argue in favor of the general principle Frege endorsed in his yesterday/today example. Since (7) is indirect discourse, its truth requires that the embedded clause agree in content with Mary's utterance. If we can use (7), as it seems we can, to report Mary's utterance of 'a unicorn is walking,' then it must be that we can indeed, as Frege said, express today what she expressed yesterday using the present tense, by replacing that with the past tense.

But perhaps this is too quick. While we're on Fregean territory, we may note that we can also report Gustav Lauben's utterance of 'I am wounded,' by saying (8):

(8) Lauben said that he is wounded,

provided we understand the pronoun reflexively. ${ }^{14}$ Interestingly, Frege took a different view of this situation than he did of the temporal indexicals, and famously claimed that neither this nor anything anyone else can say or think can have the very same content as Lauben's first person utterance. ${ }^{15}$ This doctrine is highly problematic, however, since it puts first-person thoughts beyond the reach of the understanding of others.

A sensible compromise position on these indexical thoughts and others might begin by allowing that perhaps we shouldn't hold out for the claim that these adjustments to the expression of thought due to variation in personal, temporal, or spatial perspective preserve exactly the same contents as the original utterances whose contents they aim to track. But it seems strained to hold that no one can really understand what Mary said once time has moved on, or that no one can really understand another's first person utterances. The very fact that (8) and (7) are perfectly idiomatic and surely in some sense correct reports of utterances made from a different personal or temporal point of view suggests that, whether or not they preserve exactly the same content, their embedded sentences express thoughts that are properly coordinated with the original thinkers', in such a way as to manifest the understanding by the reporter of the original thinker's thoughts. In the case of tense, such a view would entail that McTaggarts's (3') holds: tensed judgments must be understood in relation to a point of view. But it allows that the point of view of the hearer need not be exactly the same as that of the original speaker or thinker. Perhaps this means that strictly speaking, the thoughts are not identical in content. But it may be claimed that as long as the hearer can locate the original thinker's temporal perspective relative to his own in the manner exhibited by the alternative interpretation of (8), understanding has been achieved. ${ }^{16}$ We will see shortly that there may be additional constraints on the modes of presentation of or reference to

\footnotetext{
13 Frege 1994, 522.

${ }^{14}$ It can also be understood as a demonstrative, making (8) also ambiguous.

15 Frege 1994, 524.

16 The position described in this paragraph is developed at length in Heck 2002.
} 
objects, including times, if the new thought is to count as properly coordinated with the former one.

If this is right, then one can still be a realist about tense-can still take tense seriously - while allowing that a tensed thought can be in some sense preserved in differently tensed clothing. I now want to show how this undermines a recent argument for the unreality of tense, due to A. W. Moore. After a careful investigation of what exactly we should understand the question of the reality of tense to be, Moore settles on the thesis that "the issue whether tense is real should be understood as the issue whether the truth-conditions of a tensed representation must be given by means of a representation that is itself tensed."17 In order to relate this to the previous discussion, it is useful to translate it into a slightly different terminology. The notion of truth-conditions is notoriously tricky: in one sense the sentence 'snow is white' is true iff grass is green. Perhaps we know that that is not a statement of what we mean by truth-conditions. But arguably, the same should be said of certain well-known proposals that express "truth-conditions" for tensed sentences in terms that refer to utterances and their B-relations. Consider, for example, the idea that an utterance $u$ of "Smith was ill" is true iff Smith IS ill at some time earlier than the time of $u$. This is certainly a true material bi-conditional, but does it express the "truth-conditions" of the utterance in the sense that is relevant to the theory of meaning and mental content? The relevant notion of the truth-conditions of an utterance is that the knowledge of which is sufficient for an individual to understand the utterance. Consider the knowledge that (9) expresses:

(9) Any utterance $u$ of ' $a$ was F' is true iff $a$ IS F at some time earlier than the time of $u$.

Knowledge of (9) does not suffice in and of itself to enable anyone to understand any utterances. This is because (9) does not entail any T-sentences. It entails only conditional T-sentences, such as (10):

(10) If $u$ is an utterance of ' $a$ was F', then $u$ is true iff $a$ IS F at some time earlier than the time of $u$.

To detach the T-sentence in the consequent of this conditional, the thinker must know the time of $u{ }^{18}$ Moreover, knowing when an utterance was made, like knowing who someone is, might well require some preferred way of representing that time, or that person, as the case may be. By way of comparison, consider the analog of (10) for demonstrative thoughts (here we may ignore the tense):

(11) If $u$ is an utterance of 'that is G,' then $u$ is true iff the object the speaker of $u$ demonstrated is $\mathrm{G}$.

Here the hearer must know what object the speaker demonstrated in order to understand his utterance. Moreover, not just any way of representing that object suffices for "knowing what" the speaker referred to. Suppose I overhear someone in the next room say, "that is ugly," ostensibly referring to some object in the room,

\footnotetext{
${ }^{17}$ Moore 2001, 381.

${ }^{18}$ On conditional T-sentences, see Burge 1974 and Heck 2002.
} 
which I cannot see. It is intuitive that I do not fully understand what the speaker said, for the simple reason that I do not know what he referred to. I certainly don't know what was said if all I know is that the person said of the object he was referring to that it was ugly, anymore than I know which of the two teams playing won last night's baseball game if all I know is that it was the team that scored the most runs. In the case of a perceptual demonstrative judgment, it is fairly clear that fully understanding it requires that the hearer think a properly coordinated perceptual demonstrative thought of her own. I must be able to demonstratively identify the object myself, and think, "he is saying that that is ugly." A properly coordinated demonstrative judgment is generally sufficient, as variations in spatial orientation and perspective arguably make it impossible for several people to share exactly the same point of view on the objects in a room, but surely they can all understand simple demonstrative judgments made by one another, as long as they can all see the relevant objects and one another's demonstrations.

Let's return to the issue of how to formulate the question of the reality of tense. Moore suggested that the issue is whether the truth-conditions of a tensed representation must be stated in tensed terms. I have argued that we should think instead in terms of what is required for understanding or grasping tensed thoughts and judgments. Reformulated in such terms, Moore's proposal becomes something along the lines of (12):

(12) The issue whether tense is real is the issue whether it is always necessary, for a thinker to grasp a tensed thought, that he think a tensed thought of his own.

Moore argues that his condition involving tensed truth-conditions can be reformulated in terms of a condition on points of view in truth-conditions, namely: "the issue whether tense is real is the issue whether the truth-conditions of a representation from a temporal point of view must be given by means of a representation that is from that very same point of view." ${ }^{19}$ Translating this into what is required for grasping a judgment, we would have

(13) the issue whether tense if real is the issue whether it is always necessary, for a thinker to grasp a tensed thought, that he adopt the same point of view as the original thinker, and think a thought from that point of view.

Note that on the face of it, (13) is considerably stronger than (12). The more modest claim (14) seems to have gone missing from Moore's analysis:

(14) The issue whether tense is real is the issue whether it is always necessary, for a thinker to grasp a tensed thought, that he think a thought from some particular temporal point of view (not necessarily that of the original thinker).

Actually, (14) isn't missing; Moore argues against it as an adequate gloss on (12). ${ }^{20} \mathrm{He}$ claims that if, in keeping with (14), we allow some variation in the tensed formulation of a thought, as a way of taking into account our changed temporal perspective on that thought, then anything goes, and nothing can prevent us from

\footnotetext{
${ }^{19}$ Moore 2001, 383.

${ }^{20}$ More exactly, he argues against the analogue of (14) stated in terms of truth-conditions, but I omit this qualification here and henceforth.
} 
formulating the thought, and in particular identifying the time of the thought, in anyway whatsoever, including by means of tenseless identifications of the time, provided such exist (and we may assume they do exist). But this would obviously be inconsistent with (12).

Now, we have already seen reason for thinking that it isn't in general true for indexical or demonstrative thoughts that allowing some variation in the form of identification of the object leads to a slippery slope that lets in anything. To understand a perceptual demonstrative, a hearer has to think a properly coordinated demonstrative thought. It doesn't have to be exactly the same thought, but no thought involving, say, a descriptive identification of the object would suffice for understanding. Similarly, if Gustav says to me, "I am wounded," I presumably represent to myself what he is saying in the form, "you are wounded." Use of his proper name would not be an admissible alternative way of expressing what he is saying, for his wound might have induced amnesia. Finally, Mary's unicorn utterance of yesterday may be adequately reported today using an updated tensed formulation as in the second reading of (8). But it hardly follows that I can accurately report what she said yesterday using (15), provided only that the lunar event it describes was simultaneous with Mary's utterance:

(15) Mary said that a unicorn was walking at the time of the most recent lunar eclipse.

So Moore's argument for (13) as the only acceptable gloss on (12) is not cogent. Moreover, (13) has highly counterintuitive consequences. It entails that if tense is real, then for me to grasp what my friend is telling me in the postcard he sent several days ago, which just arrived today, and which says, 'it's raining today,' I must think a thought that is only available to me if I get myself into the temporal point of view that my friend occupied when he wrote the card. If (13) is true, then the reality of tense requires the possibility of time travel! Or, if that is impossible, we must admit that tensed judgments made from different temporal standpoints are simply incommensurable, and the unity of time as a single field of events that we can all think and talk about cannot be maintained. To persist in defending the reality of tense, one would have to admit that reality splits into distinct and incompatible temporal "worlds."

Not surprisingly, Moore concludes that tense cannot be real. But I have argued that his reasoning turns on an unreasonably strong construal of what is required for it to be real. Contrast this with McTaggart's argument, in which the consequences of a modest and reasonable realism about tense-something consistent with (14) - are drawn out until the last minute when the boom is lowered in the form of his principle (5). I think Moore's refusal to take (14) seriously is akin to Lowe's outright rejection of McTaggart's compound tenses. ${ }^{21}$

\footnotetext{
${ }^{21}$ Ironically, Lowe is a realist about tense. He thinks with McTaggart that change cannot be understood apart from tensed concepts. His suggested way of understanding change involves "an imaginative projection. . . we must understand what it would be to use the words 'now' and 'here' correctly at other times and places. . . such an understanding is essential to an understanding of the very meaning of words like 'now' and 'here' (how else could we communicate across time and space?)" (Lowe 1987, 69). How else indeed? But that is precisely the reason why some flexibility of the sort McTaggart envisions is an essential aspect of tensed thought.
} 
McTaggart allows that up to a point, disparate temporal perspectives can be made intelligible to one another. This must itself be done from a temporal perspectivethough not necessarily that of the original thinker. In light of the the facts about tensed speech and thought canvassed above, this seems to be a reasonable account of how we actually do go about understanding judgments made from other temporal perspectives.

Go back to the example of the postcard. I do understand what my friend wrote, so how do I do it? I don't do it by taking up his temporal perspective, at least not literally. But perhaps I can simulate the past perspective imaginatively. I take up in imagination my friend's point of view and use it to understand what he wrote as if he had uttered the sentence to me on the phone at the time. We may think of this as similar to the imaginative adoption of another person's point of view in an effort to understand his mental state. A good question to ask at this point is, where could I have acquired this ability to adopt in imagination other temporal points of view? A plausible suggestion is that experiential or autobiographical memory itself provides us with such an ability, in the form of what John Campbell has dubbed "temporal de-centering." ${ }^{, 2}$ It is fundamental to experiential memory that a veridical memory preserves certain crucial features of a past perceptual experience. The contents of perceptual experience are clearly mostly in present tense (that man is walking, that apple is red, etc.) Somehow, this presence is preserved in memory imagery, although the memory as a whole represents the perceptual encounter as being in the past. When I recall my friend's wedding, I grasp again the present-tensed contents I previously entertained perceptually and cognitively, for example, he is nervous. Of necessity I grasp them from a temporal point of view, as (3') and (14) require. But my grasp of those contents locates them in time relative to the present- that's why I would never confuse my memory image with a current perception with the content that he is nervous. My memory image retains something of the immediacy or presentness of the perceptual experience from which it derives. But it represents that presentness as past. Memory thus seems to represent events and objects as, in effect, present in the past. If this is right, then we have a further vindication of McTaggart's secondorder tenses - at least if we leave them in the form that includes the tensed copula. This way of looking at memory involves abandoning the uncompromising and problematic realism that (13) expresses, which is incompatible with the unity of time. But it is consistent with the modest realism about tensed thought expressed in (14).

\section{Conclusion}

I have argued that the McTaggart-Dummett argument is a plausible interpretation of the historical McTaggart's reasoning in "The Unreality of Time." I have also argued that even if we reject it on the grounds that its second premise is false, the second part of the argument should command our attention as a self-standing

${ }^{22}$ Campbell 2001. 
argument for the unreality of tense, where this is understood as a kind of eliminativism about tense, at least for the purpose of "liming the nature of reality," in Quine's famous phrase. So understood, it bears comparison to more recent arguments for the unreality of tense given by B-theorists such as Mellor, with the Parmenidean premise (5) playing the role that is played in the more recent arguments by scientific realism and the primacy of the B-theoretic representation of space or space-time that is familiar from modern physics. This part of McTaggart's argument cannot be dismissed, as Lowe has argued it should, as being guilty of a fundamental misunderstanding of the nature of tense or indexicality. Indeed, I have argued that the use McTaggart makes of compound tense predications is defensible in light of our actual practices of interpreting tensed speech and thought. That practice is more complex than Lowe recognizes, and incorporates a variety of mechanisms for negotiating and crossreferencing distinct temporal points of view, while never abandoning the connection to some point of view.

According to the McTaggart-Dummett argument, even this relatively weak and flexible commitment to points of view means that we must adopt an anti-realist attitude to tense. I have not, the reader will note, endorsed this reasoning, and have contented myself with attempting to clarify some of the issue at stake in debates about the unreality of tense. In fact, I reject premise (5), and eliminativism or antirealism about tense as well. Why have I labored so hard to defend the McTaggartDummett argument against Lowe's charges if I think it is ultimately unsound? Because I believe that the best defense against tense-eliminativism is a good offense. I think the case can be made that the possession and deployment of tensed concepts is indispensable for the representation and understanding of numerous aspects of reality, including agency and personhood. An important part of that case will involve an appreciation of the complex pattern of negotiating and cross-referencing among different temporal points of view of which, I have argued, Lowe takes insufficient account, and which, I have also argued, pace Moore, is consistent with a reasonable understanding of what it is for tense to be real. I mentioned briefly how such negotiating among different temporal points of view is involved in autobiographical memory. I doubt that memory can be understood without the employment of tensed concepts. Because of the importance of memory to the concept of a person, I think eliminativism about tense would entail eliminativism about personhood, and therewith also agency. Finally, because of the role of agency in thought (recall that the drawing of an inference is an action, albeit a mental action), tense-eliminativism would force us to adopt an anti-realist attitude toward rational thought itself - a form of cognitive suicide. ${ }^{23}$ McTaggart-Dummett has taught us something very important: that fundamental features of tensed speech and thought are inconsistent with the Parmenidean ideal of a complete description of reality from no particular point of view. I hope to show elsewhere that the proper conclusion to be drawn is that that ideal should be abandoned.

\footnotetext{
${ }^{23}$ Mellor 1998 acknowledges that tensed thought is essential for agency, but his eliminativism about tense commits him to the view that tensed thoughts are not essential to understanding agency. This seems to entail that in Mellor's view, it is possible to understand agency without being an agent. I believe this to be untenable. For some connections between memory, agency, and personhood, see Burge 2003.
} 
Acknowledgements I thank the participants in the WVU "Time on Trial" Conference for their helpful comments. Special thanks to Ernani Magalhaes for his work in organizing the conference, and for making our weekend in Morgantown so memorable. The paper also benefited from the comments of two anonymous referees for Philosophia.

Open Access This article is distributed under the terms of the Creative Commons Attribution Noncommercial License which permits any noncommercial use, distribution, and reproduction in any medium, provided the original author(s) and source are credited.

\section{References}

Burge, T. (1974). Demonstrative constructions, reference and truth. Journal of Philosophy, 71, $205-223$.

Burge, T. (2003). Memory and persons. Philosophical Review, 112(3), 289-337.

Campbell, J. (2001). Memory demonstratives. In T. McCormack \& C. Hoerl (Eds.), Time and memory. Oxford: OUP.

Dummett, M. (1960). A defense of McTaggart's proof of the unreality of time. Philosophical Review, 69 (4), 497-504.

Frege, G. (1994). The thought: A logical inquiry. In R. Harnish (Ed.), Basictopics in philosophy of language. Englewood Cliffs: Prentice-Hall.

Hardin, C. L. (1988). Color for philosophers. Expanded Edition. Hackett.

Healey, R. (2001). Can physics coherently deny the reality of time? In C. Callender (Ed.), (2001). Time, reality, and experience. Cambridge: CUP.

Heck, R. (2002). Do demonstratives have senses? Philosophers' Imprint, 2(2), 1-33.

Higginbotham, J. (1995). Tensed thoughts. Mind and Language, 10(3), 226-249.

Lowe, E. (1987). The indexical fallacy in McTaggart's proof of the unreality of time. Mind, 96(381), 62-70.

McTaggart, J. (1908). The unreality of time. Mind, 17(68), 457-474.

McTaggart, J. (1921). The nature of existence. Cambridge: CUP.

Mellor, D. H. (1998). Real time II. Routledge.

Moore, A. (2001). Apperception and the Unreality of Tense. In T. McCormack \& C. Hoerl (Eds.), Time and memory. Oxford: OUP.

Nagel, T. (1989). The view from nowhere. Oxford: OUP.

Partee, B. (1973). Some structural analogies between tenses and pronouns in English. Journal of Philosophy, 70(18), 601-609.

Price, H. (1996). Time's arrow and Archimedes point: New directions for the physics of time. Oxford: OUP.

Putnam, H. (1967). Time and physical geometry. Journal of Philosophy, 64, 240-247.

Reichenbach, H. (1947). Elements of symbolic logic. New York: MacMillan.

Stroud, B. (2000). The quest for reality. Oxford: OUP.

Williams, B. (1978). Descartes. Harmondsworth: Penguin. 